\title{
Nickel(II), Copper(I) and Copper(II) Complexes of Bidentate
}

\section{Heterocyclic Thiosemicarbazones}

\author{
Rejane Lúcia de Lima, Letícia Regina de Souza Teixeira, \\ Tania M. Gomes Carneiro, and Heloisa Beraldo* \\ Departamento de Química, Universidade Federal de Minas, \\ 31270-901 Belo Horizonte - MG, Brazil
}

\begin{abstract}
Complexos de tiossemicarbazonas derivadas de 3- e 4-formilpiridina (H3FPT e H4FPT) e 3- e 4-acetilpiridina (H3APT e H4APT) com níquel(II) e cobre(I) ou cobre(II) foram preparados e caracterizados através de microanálises, medidas de condutividade molar e susceptibilidade magnética e por meio de seus espectros de infravermelho e de R.M.N., no caso dos complexos de cobre(I) e dos complexos diamagnéticos de níquel(II).
\end{abstract}

Nickel(II) and copper(I) or copper(II) complexes of thiosemicarbazones derived from 3- and 4-formylpyridine (H3FPT and H4FPT) and 3- and 4-acetylpyridine (H3APT and H4APT) have been prepared and characterized by microanalyses, molar conductivity and magnetic susceptibility measurements and by their NMR (in the case of copper(I) and diamagnetic nickel(II) complexes) and IR spectra.

Keywords: heterocyclic thiosemicarbazones, bidentate thiosemicarbazones, nickel(II), copper(I), copper(II)

\section{Introduction}

Thiosemicarbazones and their metal complexes are a broad class of biologically active compounds ${ }^{1}$. Metal complexes of N-heterocyclic thiosemicarbazones derived from 2-formylpyridine (H2FPT) and 2-acetylpyridine (H2APT) were extensively described in the literature ${ }^{2}$, but very few works deal with those derived from 3- and 4-formylpyridine (H3FPT, H4FPT, Fig. 1) and 3- and 4-acetylpyridine<smiles>[R]C(=NN([2H])C(N)=S)c1cccnc1</smiles>

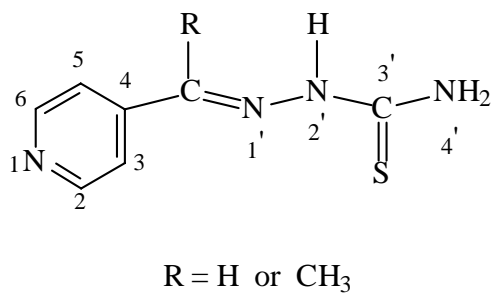

Figure 1. Structures of thiosemicarbazones derived of 3- and 4-formylpyridine and 3- and 4-acetylpyridine.
(H3APT, H4APT, Fig. 1). In some cases, lowering of the thiosemicarbazone's denticity leads to a decrease of activity $^{2}$ but the literature reports examples of biologically significant bidentate thiosemicarbazones. The compound p-acetamidobenzaldehyde thiosemicarbazone, for example, known as thioacetazone, is employed in the clinical treatment of tuberculosis ${ }^{3}$ and functions as a potential N-S bidentate ligand. In previous works we studied the iron(II), iron(III), copper(II) and zinc(II) complexes of H2FPT and $\mathrm{H} 2 \mathrm{APT}^{4-7}$. In the present article we report the syntheses and characterization of complexes of H3FPT, H4FPT, H3APT and H4APT with nickel(II), and copper(I) or copper(II).

\section{Experimental}

IR spectra were recorded by means of a Perkin Elmer 283B spectrometer using Nujol mulls between CsI plates and NMR spectra with a Brucker DRX-400 Avance (400 $\mathrm{MHz}$ ) spectrometer. The thermogravimetric data were obtained in dynamic air atmosphere at $10{ }^{\circ} \mathrm{C} / \mathrm{min}$ in the 25 $750{ }^{\circ} \mathrm{C}$ range, by using a Mettler TA 4000 TG50 analyzer. A YSI model 31 conductivity bridge was employed for molar conductivity measurements. The magnetic susceptibilities of the solids were measured at room temperature with a Johnson Matthey Magnetic Susceptibility balance. 
Partial elemental analyses were performed using a Perkin Elmer 240 equipment.

H3FPT, H4FPT, H3APT and H4APT were obtained by refluxing an ethanolic solution of 3- or 4-formylpyridine and 3- or 4-acetylpyridine with thiosemicarbazide (all purchased from Aldrich Chemical Company and used without purification) as described in the literature ${ }^{8}$. The complexes were prepared by refluxing ethanolic solutions of the thiosemicarbazone and the metal(II) perchlorate in molar ratio M:L 1:2 during 5-6 h. In the case of H3APT and H4APT the reaction with copper(II) perchlorate gave the copper(I) complexes (vide infra). The solids that formed on cooling were filtered off, washed with ethanol then ether and dried. The yields were $50-65 \%$ in the case of the nickel(II) complexes, $66-70 \%$ in the case of the copper(I) complexes and $56 \%$ in that of the copper(II) complexes.

\section{Results and Discussion}

Table 1 lists the colors, partial elemental analyses and molar conductivities of the nickel(II), copper(I) and copper(II) complexes. Thiosemicarbazones can coordinate metal ions as neutral ligands (HTSC) or as anionic species (TSC) upon deprotonation at the $\mathrm{N}\left(2^{\prime}\right)^{4,5,7}$.

The C, H, N data indicate that the copper(II) complexes of H3FPT and H4FPT present two anionic bidentate ligands per metal ion, as supported by their behavior as non-electrolytes, and their geometry is probably square planar. In contrast, both H3APT and H4APT form copper complexes in which only one neutral ligand is coordinated to the metal ion and the other coordination positions are occupied by water molecules, as confirmed by the IR spectra of the complexes (vide infra). However, in these cases the compounds are diamagnetic, suggesting reduction of copper(II) to copper(I), consistent with their yellow color and with the presence of one perchlorate as counterion in both complexes. In previous works we demonstrated that H2FPT acts as a reducing agent of its own iron(III) complex $^{6}$. The occurrence of a similar effect may now be suggested. The protonation of the ligand in the complexes was confirmed by the presence of ${ }^{1} \mathrm{H}-\mathrm{NMR}$ signals at $\delta=$ 10.503 and $\delta=11.967$, assigned to the $\mathrm{N}\left(2^{\prime}\right)-\mathrm{H}$ protons hydrogen-bonded to the DMSO solvent molecules ${ }^{9}$ (see Table 2). Also, the acetyl protons which give a signal at $\delta$ $=2.313$ and $\delta=2.329$ in the spectra of H3APT and H4APT respectively are shifted to higher frequency $(\delta=2.391$ and $\delta=2.484$ respectively) in the spectra of the copper(I) complexes due to coordination through N(1'), as observed in the literature ${ }^{10}$. Microanalyses indicate that the copper(I) complex with H3APT presents two coordinated water molecules, whereas that with H4APT presents a total of six water molecules, which are coordinated and crystallization water, as confirmed by the infrared data (vide infra), but it is not possible to determine the number of water molecules of each type in that complex. Although the loss of water does not appear separately in the thermograms of both complexes, thermogravimetric data show a residue of $\mathrm{CuO}$ corresponding to $18.8 \%$ (calcd. $20.3 \%$ ) and to $18.3 \%$ (calcd. 17.1\%) for the copper(I) complexes of H3APT and H4APT respectively, in agreement with the proposed formulations. In this case, reoxidation of copper(I) to copper(II) during the thermogravimetric measurements probably occurs.

Table 1. Colors, partial elemental analyses and molar conductivities of the metal complexes of bidentate thiosemicarbazones.

\begin{tabular}{|c|c|c|c|c|c|}
\hline Compound & Color & $\begin{array}{c}\% \text { C Found } \\
\text { (Calcd.) }\end{array}$ & $\begin{array}{c}\% \text { H Found } \\
\text { (Calcd.) }\end{array}$ & $\begin{array}{c}\% \text { N Found } \\
\text { (Calcd.) }\end{array}$ & $\Lambda_{\mathrm{M}}^{\mathrm{a}}$ \\
\hline$[\mathrm{Ni}(\mathrm{H} 3 \mathrm{FPT})(3 \mathrm{FPT})]_{\mathrm{ClO}}$ & brown & $\begin{array}{c}32.77 \\
(32.49)\end{array}$ & $\begin{array}{c}2.33 \\
(2.92)\end{array}$ & $\begin{array}{c}21.95 \\
(21.65)\end{array}$ & 77 \\
\hline$\left[\mathrm{Cu}(3 \mathrm{FPT})_{2}\right]$ & green & $\begin{array}{c}41.12 \\
(39.85)\end{array}$ & $\begin{array}{c}3.04 \\
(3.34)\end{array}$ & $\begin{array}{c}27.11 \\
(26.55)\end{array}$ & 32 \\
\hline$\left[\mathrm{Ni}(\mathrm{H} 4 \mathrm{FPT})(4 \mathrm{FPT}) \mathrm{ClO}_{4}\right.$ & green & $\begin{array}{c}32.64 \\
(32.49)\end{array}$ & $\begin{array}{c}2.41 \\
(2.92)\end{array}$ & $\begin{array}{c}21.82 \\
(21.65)\end{array}$ & 79 \\
\hline$\left[\mathrm{Cu}(4 \mathrm{FPT})_{2}\right]$ & brown & $\begin{array}{c}40.44 \\
(39.85)\end{array}$ & $\begin{array}{c}3.11 \\
(3.34)\end{array}$ & $\begin{array}{c}27.22 \\
(26.55)\end{array}$ & 34 \\
\hline$\left[\mathrm{Ni}(\mathrm{H} 3 \mathrm{APT})_{2}(3 \mathrm{APT}) \mathrm{ClO}_{4}\right.$ & brown & $\begin{array}{c}39.13 \\
(38.96)\end{array}$ & $\begin{array}{c}4.01 \\
(3.95)\end{array}$ & $\begin{array}{c}22.40 \\
(22.72)\end{array}$ & 87 \\
\hline$\left[\mathrm{Cu}(\mathrm{H} 3 \mathrm{APT})\left(\mathrm{H}_{2} \mathrm{O}\right)_{2}\right] \mathrm{ClO}_{4}$ & yellow & $\begin{array}{c}24.61 \\
(24.50)\end{array}$ & $\begin{array}{c}3.46 \\
(3.34)\end{array}$ & $\begin{array}{c}15.02 \\
(14.28)\end{array}$ & 79 \\
\hline$\left[\mathrm{Ni}(\mathrm{H} 4 \mathrm{APT})_{2}(4 \mathrm{APT}) \mathrm{ClO}_{4}\right.$ & light green & $\begin{array}{c}38.04 \\
(38.96)\end{array}$ & $\begin{array}{c}3.64 \\
(3.95)\end{array}$ & $\begin{array}{c}21.93 \\
(22.72)\end{array}$ & 88 \\
\hline$\left[\mathrm{Cu}(\mathrm{H} 4 \mathrm{APT})\left(\mathrm{H}_{2} \mathrm{O}\right)_{n}\right]\left(\mathrm{ClO}_{4}\right) \cdot(6-\mathrm{n}) \mathrm{H}_{2} \mathrm{O}^{\mathrm{b}}$ & yellow & $\begin{array}{c}20.02 \\
(20.64) \\
\end{array}$ & $\begin{array}{r}3.40 \\
(3.90) \\
\end{array}$ & $\begin{array}{c}12.14 \\
(12.05) \\
\end{array}$ & 89 \\
\hline
\end{tabular}

a: $c a \cdot 10^{-3} \mathrm{M}$ in DMF; b: $\mathrm{n}=2,3$ or 4 (see text). 
$\mathrm{C}, \mathrm{H}, \mathrm{N}$ analyses suggest that H3FPT and H4FPT form 2:1 ligand-to-metal complexes with nickel(II), in which one of the ligands is neutral and the other anionic, similar to an iron(III) complex of 2-acetylpyridine thiosemicarbazone obtained by us in a previous work ${ }^{11}$. The molar conductivity measurements indicate that both complexes are 1:1 electrolytes, consistent with the presence of the perchlorate bands in the infrared spectrum (vide infra). The complex $\left[\mathrm{Ni}(\mathrm{H} 4 \mathrm{FPT})(4 \mathrm{FPT}) \mathrm{ClO}_{4}\right.$ is diamagnetic, suggesting square planar geometry but in the case of $[\mathrm{Ni}(\mathrm{H} 3 \mathrm{FPT})(3 \mathrm{FPT})] \mathrm{ClO}_{4}$ the measured magnetic susceptibility of 3.0 BM is close to the theoretical value of $2.83 \mathrm{BM}$ of tetrahedral arrangement. The ${ }^{1} \mathrm{H}-\mathrm{NMR}$ spectrum of the former shows a peak at $\delta=11.398$, assigned to the protonated ligand's $\mathrm{N}\left(2^{\prime}\right)-\mathrm{H}$ hydrogen bonded to $\mathrm{DMSO}^{9}$. Also, the signal at $\delta=7.992$ in the spectrum of H4FPT, assigned to the formyl proton, is shifted to higher frequency $(\delta=7.998)$ upon coordination of the azomethine nitrogen N(1'). H3APT and H4APT form 3:1 ligand-to-metal complexes with nickel(II), of octahedral geometry. Microanalyses of these complexes suggest the presence of two protonated and one deprotonated bidentate ligands, which was also confirmed by the 1:1 electrolyte behavior of both complexes and by the presence of perchlorate absorptions in the IR spectrum. Although the NMR signals are broad for the paramagnetic nickel(II) complexes preventing reliable integration, the presence of resonances at $\delta=11-12$ (data not shown), characteristic of the $\mathrm{N}\left(2^{\prime}\right)-\mathrm{H}$ protons hydrogen bonded to $\mathrm{DMSO}^{9}$ confirms that at least one of the ligands is protonated.

The assignments of the IR bands useful for determining the ligand's mode of coordination are listed in Table 3 . The bands in the region $3160-3440 \mathrm{~cm}^{-1}$, attributed to the symmetrical stretching mode $\mathrm{v}\left(\mathrm{NH}_{2}\right)$ in the spectra of the ligands, shift to $3460-3210 \mathrm{~cm}^{-1}$ in those of the complexes, as a consequence of the coordination of the sulfur from the $\mathrm{C}=\mathrm{S}\left(\mathrm{NH}_{2}\right)$ group, as observed by other authors ${ }^{12}$. The $\mathrm{v}(\mathrm{C}=\mathrm{N})$ bands of the thiosemicarbazones at $c a .1590 \mathrm{~cm}^{-1}$ shift to $1625-1565 \mathrm{~cm}^{-1}$ in the spectra of the complexes, indicating coordination of the azomethine nitrogen $\mathrm{N}\left(1^{\prime}\right)$ in agreement with previous studies ${ }^{13}$. The uncomplexed thiosemicarbazones show the thioamide IV band, which possesses considerable contribution from $v(\mathrm{CS})$, in the 800 - $825 \mathrm{~cm}^{-1}$ range. This band shifts 45 to $110 \mathrm{~cm}^{-1}$ to lower energy when coordination occurs with deprotonation at $\mathrm{N}\left(2^{\prime}\right)$ and formation of a single C-S bond ${ }^{11}$. The shift is 5 to $25 \mathrm{~cm}^{-1}$ to lower frequencies when the thiosemicarbazones coordinate the metal in the neutral form ${ }^{11}$. Bands in the $355-395 \mathrm{~cm}^{-1}$ region are assigned to $v(\mathrm{M}-\mathrm{S})$ and those at $435-485 \mathrm{~cm}^{-1}$ region to $v(\mathrm{M}-\mathrm{N})$ vibrations ${ }^{13}$, supporting the coordination of all ligands as bidentate $\mathrm{N}-\mathrm{S}$ chelating agents. In the spectra of $\left[\mathrm{Cu}(\mathrm{H} 3 \mathrm{APT})\left(\mathrm{H}_{2} \mathrm{O}\right)_{2}\right] \mathrm{ClO}_{4}$ and $\left[\mathrm{Cu}(\mathrm{H} 4 \mathrm{APT})\left(\mathrm{H}_{2} \mathrm{O}\right)_{\mathrm{n}}\right] \mathrm{ClO}_{4}$. $(6-\mathrm{n}) \mathrm{H}_{2} \mathrm{O}$ there are bands at $3315,1630,605$ and $420 \mathrm{~cm}^{-1}$ and at $3420,1625,595$ and $430 \mathrm{~cm}^{-1}$ respectively, attributable to $\mathrm{v}(\mathrm{OH}), \delta\left(\mathrm{OH}_{2}\right)$, $\pi_{\mathrm{w}}\left(\mathrm{OH}_{2}\right)$ and $v_{\mathrm{Cu}-\mathrm{O}}$ of coordinated water ${ }^{13}$. Furthermore, the IR spectrum of $\left[\mathrm{Cu}(\mathrm{H} 4 \mathrm{APT})\left(\mathrm{H}_{2} \mathrm{O}\right)_{\mathrm{n}}\right] \mathrm{ClO}_{4} \cdot(6-\mathrm{n}) \mathrm{H}_{2} \mathrm{O}$ shows broad absorptions in the region $3600-3200 \mathrm{~cm}^{-1}$ characteristic of crystallization water ${ }^{14}$. Finally, a strong, broad absorption band, which is characteristic of $v_{3}$ of ionic perchlorate $^{15}$ is observable in the spectra of $\left[\mathrm{Cu}(\mathrm{H} 3 \mathrm{APT})\left(\mathrm{H}_{2} \mathrm{O}\right)_{2}\right] \mathrm{ClO}_{4},[\mathrm{Ni}(\mathrm{H} 3 \mathrm{FPT})(3 \mathrm{FPT})] \mathrm{ClO}_{4}$ and [Ni(H4FPT)(4FPT) $] \mathrm{ClO}_{4}$ at about $1070 \mathrm{~cm}^{-1}$. Also, $v_{4}\left(\mathrm{ClO}_{4}\right)$ is present as a sharp shoulder at $620 \mathrm{~cm}^{-1}$ and a weak band at $946 \mathrm{~cm}^{-1}$ may be due to $v_{1}\left(\mathrm{ClO}_{4}\right)$, suggesting that the ionic perchlorate is distorted from tetrahedral symmetry due to lattice effects or hydrogen bonding by the coordinated ligand's $\mathrm{NH}$ functions. In contrast, $\left[\mathrm{Cu}(\mathrm{H} 4 \mathrm{APT})\left(\mathrm{H}_{2} \mathrm{O}\right)_{n}\right] \mathrm{ClO}_{4} \cdot(6-\mathrm{n}) \mathrm{H}_{2} \mathrm{O}$,

[Ni(H3APT) $)_{2}(3 \mathrm{APT}) \mathrm{ClO}_{4}$ and $\left[\mathrm{Ni}(\mathrm{H} 4 \mathrm{APT})_{2}(4 \mathrm{APT})\right] \mathrm{ClO}_{4}$ show a much sharper band for $v_{3}\left(\mathrm{ClO}_{4}\right)$, a sharp band for $\mathrm{v}_{4}\left(\mathrm{ClO}_{4}\right)$ and no indication of $v_{1}\left(\mathrm{ClO}_{4}\right)$ suggesting minimal distortion from tetrahedral symmetry.

In the present work a variety of metal complexes of heterocyclic bidentate thiosemicarbazones were prepared and characterized. Copper(II) complexes of 3- and 4-formylpyridine thiosemicarbazone present two deprotonated

Table 2. ${ }^{1} \mathrm{H}-\mathrm{NMR}$ spectra (DMSO - d6) of the thiosemicarbazones and their copper(I) and diamagnetic nickel(II) complexes.

\begin{tabular}{lccc}
\hline Compound & $\mathrm{N}\left(2^{\prime}\right)-\mathrm{H}$ & $\mathrm{C}-\mathrm{H}$ & $\underline{\mathrm{H}}_{3}$ \\
\hline $\mathrm{H} 3 \mathrm{FPT}$ & 11.558 & 8.057 & - \\
$\mathrm{H} 4 \mathrm{FPT}$ & 11.666 & 7.992 & - \\
$\mathrm{H} 3 \mathrm{APT}$ & 10.303 & - & 2.313 \\
$\mathrm{H} 4 \mathrm{APT}$ & 10.450 & - & 2.329 \\
{$[\mathrm{Ni}(\mathrm{H} 4 \mathrm{FPT})(4 \mathrm{FPT})] \mathrm{ClO}_{4}$} & 11.398 & 7.998 & - \\
{$\left[\mathrm{Cu}(\mathrm{H} 3 \mathrm{APT})\left(\mathrm{H}_{2} \mathrm{O}\right)_{2}\right] \mathrm{ClO}_{4}$} & 10.503 & - & 2.391 \\
{$\left[\mathrm{Cu}(\mathrm{H} 4 \mathrm{APT})\left(\mathrm{H}_{2} \mathrm{O}\right)_{\mathrm{n}}\right]\left(\mathrm{ClO}_{4}\right) \cdot(6-\mathrm{n}) \mathrm{H}_{2} \mathrm{O}^{\mathrm{a}}$} & 11.967 & - & 2.484 \\
\hline
\end{tabular}

$\mathrm{a}: \mathrm{n}=2,3$ or 4 . 
Table 3. Infrared spectra of the heterocyclic thiosemicarbazones and their metal complexes.

\begin{tabular}{|c|c|c|c|c|c|}
\hline Compound & $v\left(\mathrm{NH}_{2}\right)$ & $v(C=N)$ & $v(\mathrm{CS})$ & $v(\mathrm{MN})$ & $v(\mathrm{MS})$ \\
\hline H3FPT & $\begin{array}{l}3320 \mathrm{~m} \\
3235 \mathrm{~m}\end{array}$ & $1585 \mathrm{~s}$ & $805 \mathrm{~s}$ & - & - \\
\hline$[\mathrm{Ni}(\mathrm{H} 3 \mathrm{FPT})(3 \mathrm{FPT})] \mathrm{ClO}_{4}$ & $\begin{array}{l}3440 \mathrm{~m} \\
3340 \mathrm{~m}\end{array}$ & $\begin{array}{l}1600 \mathrm{~m} \\
1525 \mathrm{sh}\end{array}$ & $\begin{array}{l}780 \mathrm{~m} \\
695 \mathrm{~m}\end{array}$ & $450 \mathrm{~m}$ & $365 \mathrm{~m}$ \\
\hline$\left[\mathrm{Cu}(3 \mathrm{FPT})_{2}\right]$ & $3340 \mathrm{~m}$ & $1605 \mathrm{~m}$ & $695 \mathrm{~m}$ & $420 \mathrm{~m}$ & $360 \mathrm{w}$ \\
\hline H4FPT & $\begin{array}{l}3440 \mathrm{~m} \\
3278 \mathrm{~m}\end{array}$ & $1600 \mathrm{~s}$ & $825 \mathrm{~s}$ & - & - \\
\hline$[\mathrm{Ni}(\mathrm{H} 4 \mathrm{FPT})(4 \mathrm{FPT})] \mathrm{ClO}_{4}$ & $\begin{array}{l}3440 \mathrm{~m} \\
3300 \mathrm{~m}\end{array}$ & $1625 \mathrm{~s}$ & $\begin{array}{l}805 \mathrm{~m} \\
780 \mathrm{~m}\end{array}$ & $480 \mathrm{~m}$ & $365 \mathrm{~m}$ \\
\hline$\left[\mathrm{Cu}(4 \mathrm{FPT})_{2}\right]$ & $\begin{array}{l}3360 \mathrm{~m} \\
3220 \mathrm{~m}\end{array}$ & $1615 \mathrm{~s}$ & $770 \mathrm{~m}$ & $455 \mathrm{~s}$ & $390 \mathrm{w}$ \\
\hline H3APT & $\begin{array}{l}3275 \mathrm{~m} \\
3215 \mathrm{sh}\end{array}$ & $1590 \mathrm{~m}$ & $800 \mathrm{~m}$ & - & - \\
\hline$\left[\mathrm{Ni}(\mathrm{H} 3 \mathrm{APT})_{2}(3 \mathrm{APT}) \mathrm{ClO}_{4}\right.$ & $\begin{array}{l}3405 \mathrm{~m} \\
3285 \mathrm{~m}\end{array}$ & $1575 \mathrm{w}$ & $\begin{array}{l}790 \mathrm{~m} \\
715 \mathrm{~m}\end{array}$ & $480 \mathrm{~m}$ & $380 \mathrm{w}$ \\
\hline$\left[\mathrm{Cu}(\mathrm{H} 3 \mathrm{APT})\left(\mathrm{H}_{2} \mathrm{O}\right)_{2}\right] \mathrm{ClO}_{4}{ }^{\mathrm{a}}$ & $\begin{array}{l}3410 \mathrm{~s} \\
3315 \mathrm{~s}\end{array}$ & $1565 \mathrm{~s}$ & $795 \mathrm{~m}$ & $430 \mathrm{w}$ & $380 \mathrm{w}$ \\
\hline H4APT & $\begin{array}{l}3280 \mathrm{~m} \\
3160 \mathrm{~m}\end{array}$ & $1590 \mathrm{~s}$ & $800 \mathrm{~m}$ & - & - \\
\hline$\left[\mathrm{Ni}(\mathrm{H} 4 \mathrm{APT})_{2}(4 \mathrm{APT})\right] \mathrm{ClO}_{4}$ & $\begin{array}{l}3400 \mathrm{~m} \\
3220 \mathrm{~s}\end{array}$ & $1580 \mathrm{~m}$ & $\begin{array}{l}795 \mathrm{~m} \\
695 \mathrm{~m}\end{array}$ & $435 \mathrm{w}$ & $395 w$ \\
\hline$\left[\mathrm{Cu}(\mathrm{H} 4 \mathrm{APT})\left(\mathrm{H}_{2} \mathrm{O}\right)_{n}\right]\left(\mathrm{ClO}_{4}\right) \cdot(6-\mathrm{n}) \mathrm{H}_{2} \mathrm{O}^{\mathrm{a}}$ & $\begin{array}{c}3300 \mathrm{~s} \\
3210 \mathrm{~m}\end{array}$ & $1525 \mathrm{~s}$ & $775 \mathrm{~m}$ & $440 \mathrm{w}$ & $385 \mathrm{w}$ \\
\hline
\end{tabular}

a: $\mathrm{n}=2,3$ or 4 (see text for the attributions of the vibrational bands of coordinated water).

$\mathrm{s}=$ strong; $\mathrm{m}=$ medium; $\mathrm{w}=$ weak $; \mathrm{sh}=$ shoulder .

ligand molecules per metal ion. The reaction of 3- and 4-acetylpyridine thiosemicarbazone with the copper(II) salt leads to the formation of copper(I) complexes in which the thiosemicarbazones coordinate as protonated neutral ligands, in accordance with the lower acidity constant of the acetyl derivatives, due to the electron donor inductive effect of their methyl group ${ }^{7}$. Moreover, 3- and 4-formylpyridine thiosemicarbazone coordinate nickel(II) forming 2:1 ligand-to-metal complexes having one protonated and one deprotonated ligand, of tetrahedral geometry in the first case and of square planar geometry in the latter. The thiosemicarbazones derived from 3- and 4-acetylpyridine form octahedral nickel(II) complexes of the $\mathrm{ML}_{3}$ type, in which two ligand molecules are protonated and one is deprotonated. At this stage it is worth comparing the structures of the metal complexes of 2-formyl and 2-acetylpyridine thiosemicarbazone with those of the corresponding 3- and 4- analogs. In the former the presence of the tridentate chelating N-N-S system normally favors the formation of 1:1 complexes with copper(II) of approximately square planar geometry ${ }^{2}$. In contrast, the bidentate (3- and 4-) thiosemicarbazones form copper(II) complexes with 2:1 ligand-to-metal ratios. The 2-formyl and 2-ace- tylpyridine thiosemicarbazones, as well as their 3- and 4analogs form nickel(II) complexes with a variety of geometries and different ligand-to-metal ratios but only the 2- (i.e. $\alpha)$ thiosemicarbazones can form $\mathrm{ML}_{2}$ complexes of octahedral geometry upon coordination of the tridentate N-N-S ligand ${ }^{1}$. To our knowledge the literature does not report many examples of copper(I) complexes of 2-formyl and 2-acetylpyridine thiosemicarbazone for us to establish comparisons with the 3-and 4- analogs.

In conclusion, changing the point of attachment of the lateral chain in relation to the heteroaromatic nitrogen from the 2- (i.e. $\alpha$ ) to the 3- or 4- (i.e. $\beta$ or $\gamma$ ) positions and the nature of the pyridine starting reagent (formyl or acetyl) may have influence in the structure of the metal complexes obtained and the structural differences probably affect the biological activity of these compounds.

\section{Acknowledgements}

The authors acknowledge support for their work from $\mathrm{CNPq}$, Capes and Fapemig. Helpful suggestions from professor Douglas X. West are acknowledged. 


\section{References}

1.Padhyé, S.; Kauffman, G.B. Coord. Chem. Rev 1985, 63, 127.

2. West, D.X.; Padhye, S.B.; Sonawane, P.S. Structure and Bonding 1991, 76, 1 and references therein.

3. Nandi, A.K.; Chudhuri, S.; Mazumda, S.K.; Ghosh, S. J. Chem. Soc., Perkin II 1964, 1729.

4. Beraldo, H.; Tosi, L. Inorg. Chim.Acta 1983, 75, 249.

5. Beraldo, H.; Tosi, L. Inorg.Chim.Acta 1986, 125, 173.

6. Beraldo, H.; Borges, R.H.; Fantini, E.; Rocha, M.; Tosi, L. Inorg. Chim. Acta 1990, 172, 113.

7. Borges, R.H.U.; Paniago, E.; Beraldo, H. J.Inorg.Biochem. 1997, 65, 267.

8. Anderson, F.E.; Duca, J.C.; Scudi, J.W.; J. Chem. Soc. 1951, 4697 and references therein.

9. West, D.X.; Stark, A.M.; Bain, G.; Liberta, A .E. Trans.Met.Chem. 1996, 21, 289.
10. Kovala-Demertzi, D.; Domopoulou, A.; Demetzis, A.; Valdez-Martinez, J.; Hernadez-Ortega, S.; Espinosa-Perez, G.; West, D.X.; Salberg, M.; Bain, G.; Bloom, P.D. Polyhedron 1996, 15, 2587.

11. Borges, R.H.U.; Beraldo, H.; Abras, A . J. Braz. Chem. Soc. 1997, 8, 33.

12. El-Sawaf, A.K.; West, D.X.; El-Saied, F.A.; ElBahnasawy, R.M. Inorg. Met.-Org. Chem. 1997, 27, 1127.

13. Beraldo, H.; Boyd, L.P.; West, D.X. Trans.Met.Chem. 1988, 23, 67 and references therein.

14. Chasan, D.E.; Pytlewski, L.L.; Karyannis, N.M.; Owens, C. J. Inorg. Nuclear Chem. 1978, 40, 1019.

15. Nakamoto, K. In Infrared and Raman Spectra of Inorganic and Coordination Compounds, Wiley Interscience Publication, John Wiley \& Sons, Inc.; New York, p. 251, 1986. 